(c) American Dairy Science Association, 2004.

\title{
Using Activity and Milk Yield as Predictors of Fresh Cow Disorders
}

\author{
J. L. Edwards and P. R. Tozer \\ Department of Dairy and Animal Science, \\ The Pennsylvania State University, \\ University Park 16802
}

\begin{abstract}
The objective was to determine whether daily walking activity and milk yields could be used as predictors of metabolic and digestive disorders early in lactation. Data were collected from 1996 through 1999 from 1445 dairy cows in 3 Florida herds. Walking activity, milk yield, and other measures were collected from a computerized dairy management system. Mixed models analysis was used for data on cows before their first detected estrus, as identified by difference in activity. Healthy cows were defined as those without any metabolic or digestive disorder during the prebreeding stage, whereas a sick cow had an occurrence of those disorders at any time during the prebreeding stage. Metabolic disorders were ketosis, retained placenta, and milk fever. Digestive disorders included displaced abomasum, indigestion, reduced feed intake, traumatic gastritis, acidosis, and bloat. Data from cows with known cases of ketosis, left displaced abomasum, and digestive disorders were analyzed to determine changes in activity and milk yield before those specific disorders were clinically diagnosed. Although walking activity was generally lower among sick cows, cows with ketosis, left displaced abomasum, and digestive disorders had higher than average activity 8,9 , and $8 \mathrm{~d}$, respectively, before each diagnosed disorder. Daily milk yields of sick cows were approximately $15 \mathrm{~kg} / \mathrm{d}$ less than milk yields of healthy cows. Milk yields were lower by 6,7 , and $5 \mathrm{~d}$, respectively, before diagnoses of ketosis, left displaced abomasum, and digestive disorders. Cows with ketosis, left displaced abomasum, and general digestive disorders could possibly be detected about 5 to $6 \mathrm{~d}$ earlier than clinical diagnoses based on changes in daily walking activity and milk yield.
\end{abstract}

(Key words: walking activity, fresh cow disorder, pedometer, milk yield)

Abbreviation key: LDA = left displaced abomasum.

Received: December 11, 2002

Accepted: August 20, 2003.

Corresponding author: P. R. Tozer; e-mail: ptozer@psu.edu.

\section{INTRODUCTION}

Numerous studies have shown that changes in milk production are associated with the occurrence of metabolic and digestive disorders (Fourichon et al., 1999). The effect of short- and long-term milk yield has been analyzed, as well as the effect on subsequent lactations. Varying results in lactation performance have been observed due to ketosis, retained placenta, metritis, or displacement of the abomasum. Rajala-Schultz et al. (1999) found milk yield to decrease before the diagnosis of clinical ketosis, and the loss of milk continued for at least $2 \mathrm{wk}$ after diagnosis. The loss of milk yield on the day of diagnosis reached 4 to $10 \mathrm{~kg} / \mathrm{d}$ for clinical ketosis and 1 to $3 \mathrm{~kg} / \mathrm{d}$ for the subclinical form of this disorder (King, 1979; Dohoo and Martin, 1984; Deluyker et al., 1991). Average losses for cows with left displaced abomasums (LDA) varied from 250 to $800 \mathrm{~kg}$ during a 305d lactation (Martin et al., 1978; Deluyker et al., 1991). Østergaard and Gröhn (1999) found a 4.6 and $5.2 \mathrm{~kg} / \mathrm{d}$ loss for primiparous and multiparous cows, respectively, within the first $6 \mathrm{wk}$ after diagnosis.

Electronic identification has been used in the dairy industry for many years and is the key to data flow in large herds. Through deviations from the cow's normal state, mastitis, illness, or estrus can be detected with the measurements of conductivity, milk temperature, and walking activity (Tomaszewski, 1993). Activity can be measured from a pedometer attached to a leg band or a neck chain. Because daily measurements of activity are received, changes in activity can be viewed with ease and diagnosis made for a cow with decreased activity.

There has been limited research to show the effects of cow health on daily walking activity. Researchers have shown symptoms of specific disorders to include loss of appetite and restricted movements, thus, decreasing activity (Schultz, 1988; Heinrichs et al., 1996). Moallem et al. (2002) found walking activity to be decreased by laminitis and a digestive upset of bovine ephemeral fever infection.

One possible method to identify potential health problems in dairy cows earlier than they are currently being clinically diagnosed is to use an automated system that allows monitoring of both walking activity and 
milk production. A decrease in daily walking activity, along with a decrease in milk yield, might be used as an early warning to identify potential disorders in dairy cattle. The objective of this project was to determine possibilities for predicting an occurrence of a disease before clinical diagnosis based on changes in walking activity and milk production of a dairy cow.

\section{MATERIALS AND METHODS}

\section{Animals}

The data were collected from 1996 through 1999 from 3 Florida dairy herds with a total of 1445 Holstein cows and 1535 lactations. Herd 1 had a total of 241 cows, herd 2 had a total of 846 cows, and herd 3 had 358 cows. In the original data, there were a total of 12,540 cows and 28,783 lactations. There were 10,791 cows and 26,732 lactations excluded because they did not have data before $10 \mathrm{~d}$ into the lactation. This lack of early-lactation data was not due to the data-collection process but to the data storage and retrieval method, as the data were stored in a format that was extremely difficult to retrieve in a format that could be analyzed exclusive of the original recording program. Instances of lameness or injury during the current lactation were also deleted from the analysis because the results would be skewed with the low activity of these occurrences. There were 304 cows and 516 lactations deleted due to lameness or injury. Data from cows that were culled or died before the end of the prebreeding phase remained in the dataset.

\section{Production Data}

Milk yield and walking activity were recorded from the Special Agricultural Equipment Afikim computerized dairy management system (Kibbutz Afikim, Israel). The Afikim system records daily activity from a pedometer attached to a leg band on a hind leg of the cow. Activity was measured as the average steps per hour over a 24 -h period.

\section{Physiological Stages}

Changes in walking activity were used to define the prebreeding stage. After edits were completed, data from when the cow calved until her first presumed detected estrus were further evaluated. The first presumed estrus was determined based on an increase in activity. If a cow's activity was 75 steps/h greater than the previous day's activity, estrus was assumed to have occurred. The change in activity threshold, $75 \mathrm{steps} / \mathrm{h}$, was selected based on preliminary analysis of the data to ensure that the change in activity was based on es- trous activity and not due to a cow recovering from an illness or suffering from a subclinical illness. Days in milk (DIM) within the prebreeding group were truncated at $100 \mathrm{~d}$ because there were very few observations after this point. Therefore, if estrus was detected during the first 100 DIM, the cow had fewer than 100 daily records. If estrus was not detected, the cow had 100 daily records. This study only analyzed data from the prebreeding stage because this research focused on transition cows and the detection of fresh cow disorders. A point to note is that the method used may not detect all estrous activity, because the activity of some cows may not increase above the 75 steps/h threshold. However, this would be expected to be a very low percentage of cows. Also, data for cows that were detected in estrus by management, inseminated, recorded as pregnant, and moved to another group were still analyzed in this study as these data were still relevant to the research.

\section{Healthy and Sick Groups}

Disease occurrences were recorded using Visi-Cow, a program developed by Haas Chemical Company, Inc., Mobile, AL. Diagnosis, treatment, dosage, and cost were recorded for each occurrence of an illness. A veterinarian employed by all herds diagnosed disorders based on a set of standard diagnostic procedures specified by the company. The data from the prebreeding stage were then used to separate the cows into healthy and sick groups. A healthy cow was one that did not have an occurrence of a metabolic or digestive disorder during the prebreeding stage. However, "healthy" cows may have an incidence of other diseases not included in the analysis, such as mastitis. A sick cow had a clinical occurrence and a specific disease code recorded for one of the following disorders at any time during the prebreeding stage; metabolic disorders included ketosis, retained placenta, and milk fever; digestive disorders included LDA, indigestion, reduced feed intake, traumatic gastritis (hardware disease), acidosis, and bloating. Therefore, if a cow had a specific disease code recorded and a change in activity, the change in activity was attributed to the disease rather than to estrous activity. If a cow was sick more than once during the lactation, each occurrence of sickness was analyzed. There were a total of 947 healthy cows with 1018 lactations and 498 sick cows with 517 lactations used in the analysis.

The data were further divided into specific disorders to identify differences in milk yield and activity due to ketosis and LDA. General digestive disorders included acidosis, gas, off feed, and bloat and were included as one disease because there were not enough occurrences of only one of these diseases. When cows had coincident 
illnesses, they were included with both diseases. For example, if a cow was clinically diagnosed with ketosis and left displaced abomasum on the same day or a few days apart, the cow was treated as a ketotic cow and a cow with an LDA. The number of cows with coincident or concurrent diseases was relatively small, and analyzing them as a separate group would not yield significant results, hence they were included in both disease groups.

\section{Statistical Analyses}

When analyzing factors such as diseases that have a short-term effect on activity and milk yield, the testday variable associated with the disease event will be of interest. Gröhn et al. (1999) studied the effect of ketosis on milk yield and showed the advantages of using a repeated measures technique for test-day milk yields over a single measure technique with 305-d milk yield. For this reason, a repeated measures model of daily activity or milk yield is utilized in this study.

The MIXED procedure of SAS (release 8.02) was used for statistical analysis. General forms of the models estimated for activity and milk yield were:

$$
\begin{aligned}
\mathrm{A}_{\mathrm{ijklmn}}= & \mu_{\mathrm{i}}+\alpha_{\mathrm{j}} \mathrm{DIM}+\beta_{\mathrm{k}} \text { year }+\gamma_{1} \text { Calving Season } \\
& +\delta_{\mathrm{m}} \text { Parity }+\tau_{\mathrm{p}} \text { herd }+ \text { Calving Sea- } \\
& \text { son } * \text { Parity } \\
\mathrm{Y}_{\mathrm{ijklmn}}= & \mu_{\mathrm{i}}+\alpha_{\mathrm{j}} \mathrm{DIM}+\beta_{\mathrm{k}} \text { year }+\gamma_{1} \text { Calving Season } \\
& +\delta_{\mathrm{m}} \text { Parity }+\tau_{\mathrm{p}} \text { herd }+ \text { Calving Sea- } \\
& \text { son*Parity. }
\end{aligned}
$$

$\mathrm{A}_{\mathrm{ijklmn}}$ is the activity of the $i$ th cow $j \mathrm{DIM}(\mathrm{j}=1$ to 100 ) in year $k$ calving season $l$, parity $m$ from herd $p$. When day of illness was added to the model, 21 additional parameters were added to account for changes in activity $10 \mathrm{~d}$ before, and $10 \mathrm{~d}$ after, diagnosis of the illness. Similarly, $\mathrm{Y}_{\mathrm{ijk} k \mathrm{mn}}$ is the milk yield of the $i$ th cow with other effects as listed before.

Four years (1996, 1997, 1998, and 1999) of data were included in the analysis. Season assignment was based upon the calving date. For example, if a cow calved during the winter season, all her data were included within the winter calving season, and so forth for each season. Parity was described as parities one, two, three, or four and greater. For the activity model, $10 \mathrm{~d}$ before, the day of diagnosis, and up to $10 \mathrm{~d}$ after day of diagnosis were initially included in the model; however, of those $21 \mathrm{~d}$, only $3 \mathrm{~d}$ before, and up to $2 \mathrm{~d}$ after, an illness were included in the final model. Independent variables in the models of activity and milk yield for specific disorders were added or deleted based on the significance level of those variables. Random measures of DIM by cow were used to account for the model variation
Table 1. Mean activity of healthy and sick cows during each lactation and calving season.

\begin{tabular}{lllllll}
\hline & \multicolumn{2}{l}{ Healthy cows } & & \multicolumn{2}{c}{ Sick cows } & \\
\cline { 2 - 3 } & $\begin{array}{l}\text { Mean } \\
\text { activity } \\
\text { (steps/h) }\end{array}$ & SE & & $\begin{array}{c}\text { Mean } \\
\text { activity } \\
\text { (steps/h) }\end{array}$ & SE & $P$-value \\
\hline Lactation & & & & & & \\
1 & 174 & 0.6 & 165 & 4.0 & $<0.0001$ \\
2 & 151 & 0.7 & 137 & 4.1 & $<0.0001$ \\
3 & 145 & 0.9 & 137 & 4.1 & $<0.0001$ \\
4 and greater & 139 & 1.4 & 128 & 4.2 & $<0.0001$ \\
Calving season & & & & & \\
Winter & 157 & 1.1 & 145 & 4.1 & $<0.0001$ \\
Spring & 157 & 1.2 & 144 & 4.2 & $<0.0001$ \\
Summer & 146 & 0.7 & 141 & 4.1 & $<0.0001$ \\
Fall & 149 & 0.7 & 137 & 4.0 & $<0.0001$ \\
\hline
\end{tabular}

among cows. Statistical significance was declared at a probability level of $\leq 0.05$ and a trend was declared at a probability level of $\leq 0.10$.

\section{RESULTS AND DISCUSSION}

\section{Activity of Healthy and Sick Cows}

Walking activity of healthy and sick dairy cows in the prebreeding stage of lactation is presented in Table 1. Across parity groups, the mean walking activity for sick cows was 8 to 14 steps $/ \mathrm{h}(P<0.001)$ less than the activity of healthy cows. Mean activity for sick cows during each calving season was 5 to 13 steps/h $(P<$ 0.001 ) less than the activity for healthy cows. The variability of activity for sick cows was much greater than the variability of activity for healthy cows.

Healthy dairy cows walk more in winter and spring than in summer and fall $(P<0.001)$. As the temperature rises in the summer and fall calving seasons, cows tend to be less active, showing less estrous behavior and eating less. This is in contrast to Perera et al. (1986) who showed that dairy cows lie down more during winter than in summer. However, the study by Perera et al. (1986) showed that eating behavior in the winter was $5.6 \mathrm{~h} / \mathrm{d}$ and decreased to $4.2 \mathrm{~h} / \mathrm{d}$ during the summer, thus increasing their activity slightly during the winter.

The change in activity for year, calving season, lactation, and herd effects when all cows, sick and healthy, were included in the model is presented in Table 2 . This table shows that there are significant changes in activity across years $(P<0.001)$ as well as seasons as discussed previously. Comparing the activity of cows across lactations showed that cows in their first lactation had higher $(P<0.01)$ activity than cows in later lactations. This relatively high activity difference is probably due to negative social behavior within the milking herd (Grant and Albright, 1995). A significant 
Table 2. Regression model results for activity adjusted for year, calving season, lactation, and herd for all cows, sick and healthy, in the prebreeding stage.

\begin{tabular}{lccc}
\hline & $\begin{array}{c}\Delta^{1} \text { in activity } \\
\text { (steps/h) }\end{array}$ & SE & $P$-value \\
\hline Year compared to 1996 & & & \\
$\quad 1997$ & -4.47 & 0.70 & $<0.0001$ \\
1998 & -12.75 & 0.85 & $<0.0001$ \\
1999 & -10.06 & 1.67 & $<0.0001$ \\
Calving season compared to winter & & & \\
$\quad$ Spring & -2.55 & 1.09 & 0.02 \\
$\quad$ Summer & -10.36 & 0.92 & $<0.0001$ \\
Fall & -8.02 & 0.86 & $<0.0001$ \\
Lactation compared to 4 & & & \\
and greater lactations & & & \\
$\quad 1$ & 36.73 & 1.08 & $<0.0001$ \\
2 & 13.35 & 1.11 & $<0.0001$ \\
3 & 6.65 & 1.18 & $<0.0001$ \\
Herd compared to herd 3 & & & \\
1 & -67.23 & 0.79 & $<0.0001$ \\
2 & -85.37 & 0.69 & $<0.0001$ \\
\hline $1 \Delta$ = Change. & & &
\end{tabular}

difference $(P<0.001)$ in activity across herds was also identified. The difference in activity across herds could be due to differences in distances to the milking parlor from the cow barns, different feeding strategies, and other herd-specific factors.

Table 3 shows the change in activity when day of illness was added to the activity regression model for cows diagnosed with a metabolic or digestive disorder compared to healthy cows. The activity at $d-2$ to -1 , relative to the day the illness was diagnosed (d 0), was significantly different from cows without a presence of a disease $(P<0.001)$. The greatest difference in activity occurred at $1 \mathrm{~d}$ before the illness, with sick cows walking 15 fewer steps/h $(P<0.001)$ compared with healthy cows. This difference between sick and healthy cows could possibly be caused by sick cows having a loss of appetite and spending less time at the feed bunk, restricted movements, and spending more time lying down (Schultz, 1988). These symptoms of unhealthy cows could affect their walking activity.

Table 3. Regression model results for activity of cows diagnosed with a metabolic or digestive disorder adjusted for day of illness with $3 \mathrm{~d}$ before and $2 \mathrm{~d}$ following the day of diagnosis ( $\mathrm{d} 0$ ) compared with healthy cows in all herds in the pre-breeding stage.

\begin{tabular}{lccc}
\hline $\begin{array}{l}\text { Day of illness } \\
\text { compared to day of } \\
\text { diagnosis of a disease }\end{array}$ & $\begin{array}{l}\Delta^{1} \text { in activity } \\
\text { (steps/h) }\end{array}$ & SE & $P$-value \\
\hline-3 & -5.16 & 3.89 & 0.18 \\
-2 & -12.89 & 3.66 & $<0.001$ \\
-1 & -15.45 & 3.21 & $<0.0001$ \\
0 & -13.54 & 2.40 & $<0.0001$ \\
1 & -8.80 & 2.83 & 0.002 \\
2 & -0.30 & 2.87 & 0.92 \\
\hline
\end{tabular}

${ }^{1} \Delta=$ Change.

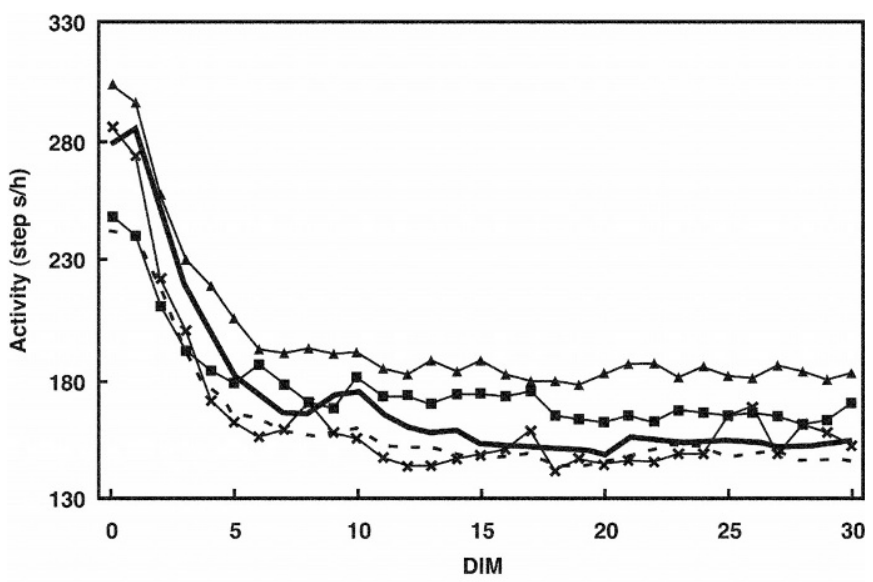

Figure 1. Mean activity for first 30 DIM for healthy (-) and sick (-1.) cows (all metabolic and digestive disorders), and cows with occurrences of ketosis ( $\mathbf{\square})$, left displaced abomasum (LDA, $\mathbf{\Delta}$ ), and digestive disorders $(x)$. Activity of healthy cows differed $(P<0.05)$ from sick cows for the first 14 DIM and occasionally thereafter. Activity of cows with LDA was higher than healthy cows every day but $\mathrm{d} 2$. Ketotic cows had lower activity than healthy cows up to $\mathrm{d} 5$, and then were more active after d 12 . Cows clinically diagnosed with general digestive disorders had lower activity than sick cows after $\mathrm{d} 4$.

\section{Effects of Specific Diseases on Activity}

Three specific diseases-ketosis, LDA, and general digestive disorders-were analyzed to examine differences in activity compared with the average of sick cows. The average DIM $( \pm \mathrm{SE})$ on the day of the diagnosis for ketosis, LDA, and digestive disorders were $10 \pm$ $8.2,14 \pm 11.9$, and $23 \pm 21.5 \mathrm{~d}$, respectively. Figure 1 presents the mean daily activity for the first 30 DIM for healthy and sick cows, as well as cows that were clinically diagnosed with ketosis, LDA, or general digestive disorders. The activity of healthy cows was significantly different from sick cows for the first 14 DIM $(P<0.05)$. After $14 \mathrm{DIM}$, differences were usually not significant $(P>0.05)$; however, there were individual days when activity did differ significantly. The activity of cows diagnosed with a disease varied. In general, the activity of cows diagnosed with an LDA was higher than healthy cows, and this difference was significant for every day but $d 2$. Ketotic cows had lower activity $(P<0.01)$ than healthy cows up to $\mathrm{d} 5$, and then became more active after $d 12$. Cows clinically diagnosed with general digestive disorders had lower activity $(P<0.01)$ than sick cows after $d 4$, indicating that when cows have these disorders they were not active. The activity of sick cows with diseases other than ketosis, LDA, or general digestive upsets was not examined. However, from Figure 1, it appears that the activity of sick cows in those categories was lower than for cows with the diseases studied. 
Table 4. Mean milk yield of healthy and sick cows during each lactation and calving season.

\begin{tabular}{|c|c|c|c|c|c|}
\hline & \multicolumn{2}{|c|}{ Healthy cows } & \multicolumn{2}{|c|}{ Sick cows } & \multirow[b]{2}{*}{$P$-value } \\
\hline & $\begin{array}{l}\text { Mean milk } \\
\text { yield (kg/d) }\end{array}$ & $\mathrm{SE}$ & $\begin{array}{l}\text { Mean milk } \\
\text { yield (kg/d) }\end{array}$ & SE & \\
\hline \multicolumn{6}{|l|}{ Lactation } \\
\hline 1 & 28.01 & 0.08 & 25.90 & 0.55 & $<0.0001$ \\
\hline 2 & 39.37 & 0.09 & 26.79 & 0.56 & $<0.0001$ \\
\hline 3 & 40.77 & 0.11 & 25.38 & 0.56 & $<0.0001$ \\
\hline 4 and greater & 37.71 & 0.17 & 15.24 & 0.58 & $<0.0001$ \\
\hline \multicolumn{6}{|l|}{ Calving season } \\
\hline Winter & 40.08 & 0.14 & 24.46 & 0.56 & $<0.0001$ \\
\hline Spring & 35.84 & 0.15 & 25.22 & 0.57 & $<0.0001$ \\
\hline Summer & 32.37 & 0.10 & 19.33 & 0.56 & $<0.0001$ \\
\hline Fall & 37.57 & 0.08 & 24.31 & 0.55 & $<0.0001$ \\
\hline
\end{tabular}

\section{Daily Milk Yield of Healthy and Sick Cows}

The milk yield of healthy and sick cows was analyzed to see whether using milk yield, along with activity, as a predictor of fresh cow disorders would give more accurate results. The mean milk yield for healthy and sick cows for each lactation and each calving season is presented in Table 4 . The milk yield of sick cows was lower $(P<0.01)$ than healthy cows in every lactation and every season; the difference in milk yield across lactations ranged from $2.11 \mathrm{~kg} / \mathrm{d}$ in first lactation to $22.46 \mathrm{~kg} / \mathrm{d}$ in lactation four and greater. A smaller range of differences, 10.62 to $15.62 \mathrm{~kg} / \mathrm{d}$, was observed when comparing the yield of healthy and sick cows across calving seasons. Another point to note in Table 4 is the variability of yields between sick and healthy cows. Healthy cows had smaller relative yield variations than the yield variations of sick cows. The results of the daily milk yield model when the day of illness was added are presented in Table 5. From $10 \mathrm{~d}$ before to $10 \mathrm{~d}$ after the diagnosis of a disease, milk yields of sick cows were lower $(P<0.01)$ than milk yields of healthy cows. Differences in milk yield became increasingly greater from 3 $\mathrm{d}$ before to $3 \mathrm{~d}$ after the day of diagnosis. The most common reason for this effect is that sick cows are less likely to spend a significant amount of time at the feed bunk, lowering DMI, thus lowering daily milk yield (Heinrichs et al., 1996).

\section{Effects of Specific Diseases on Milk Yield}

The milk yields for cows clinically diagnosed with ketosis, LDA, or general digestive disorders were not significantly different from the mean milk yield of sick cows (Figure 2). Mean yield for sick cows is not shown, as it followed a similar pattern to ketotic cows and could not be differentiated graphically. Healthy cows had lower milk yield than cows with LDA in the first $5 \mathrm{~d}$ of lactation, and then the yield of cows with LDA fell below
Table 5. Regression model results for daily milk yield adjusted for day of illness with $10 \mathrm{~d}$ before and $10 \mathrm{~d}$ following the day of diagnosis (d 0) compared to cows without an instance of a disease in all herds in the prebreeding stage.

\begin{tabular}{lllc}
\hline $\begin{array}{l}\text { Days of illness } \\
\text { compared to day of } \\
\text { diagnosis of a disease }\end{array}$ & $\begin{array}{l}\Delta \text { in } \\
\text { milk yield } \\
(\mathrm{kg} / \mathrm{d})\end{array}$ & $\mathrm{SE}$ & $P$-value \\
\hline-10 & -2.19 & 0.70 & 0.002 \\
-9 & -1.45 & 0.63 & 0.02 \\
-8 & -2.24 & 0.62 & $<0.001$ \\
-7 & -1.81 & 0.58 & 0.002 \\
-6 & -1.95 & 0.55 & $<0.001$ \\
-5 & -2.55 & 0.52 & $<0.0001$ \\
-4 & -2.86 & 0.50 & $<0.0001$ \\
-3 & -3.72 & 0.48 & $<0.0001$ \\
-2 & -4.90 & 0.45 & $<0.0001$ \\
-1 & -5.46 & 0.39 & $<0.0001$ \\
0 & -6.62 & 0.30 & $<0.0001$ \\
1 & -7.78 & 0.35 & $<0.0001$ \\
2 & -7.48 & 0.36 & $<0.0001$ \\
3 & -7.90 & 0.36 & $<0.0001$ \\
4 & -7.12 & 0.36 & $<0.0001$ \\
5 & -6.56 & 0.36 & $<0.0001$ \\
6 & -6.50 & 0.36 & $<0.0001$ \\
7 & -6.12 & 0.35 & $<0.0001$ \\
8 & -6.22 & 0.34 & $<0.0001$ \\
9 & -5.81 & 0.31 & $<0.0001$ \\
10 & -4.99 & 0.25 & $<0.0001$ \\
\hline
\end{tabular}

${ }^{1} \Delta=$ Change

that of healthy cows. In the first $5 \mathrm{~d}$ of lactation, the yield of healthy cows was not statistically different to that of cows with ketosis or digestive upsets. The mean yield for cows clinically diagnosed with LDA was more affected than previously mentioned disorders. On most

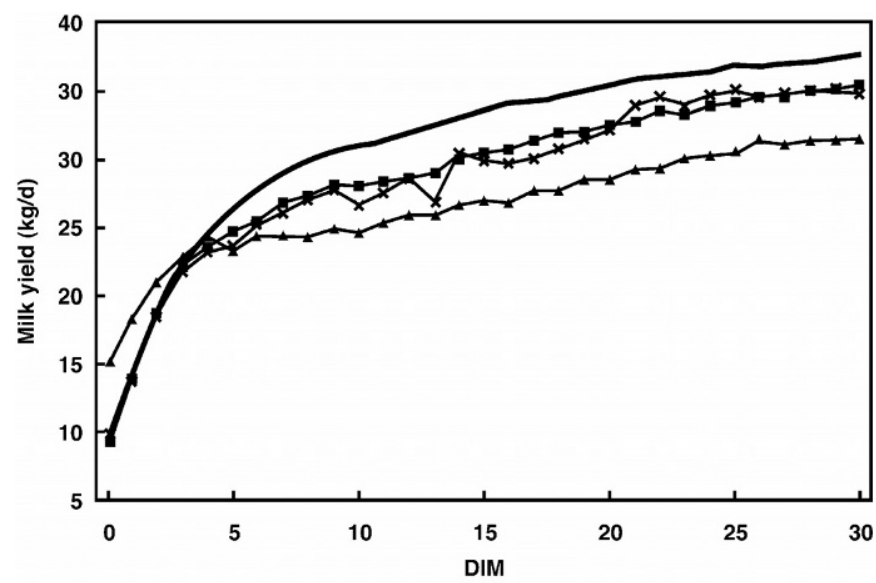

Figure 2. Mean daily milk yield for first 30 DIM for healthy (一) cows compared with cows with occurrences of ketosis (ם), left displaced abomasum (LDA, $\mathbf{\Delta}$ ), and digestive disorders $(\times)$. Milk from cows with LDA was higher in the first $5 \mathrm{~d}$ of lactation and then yields were below that of healthy cows. Yields of healthy cows differed $(P$ $<0.05$ ) from those with ketosis or digestive upsets after d 5 . On most days after $\mathrm{d} 7$, yield for cows with LDA was lower than healthy cows or those with other disorders. 
days after $d 7$, the yield for cows with LDA was significantly lower than healthy cows or those with the other disorders studied, as seen in Figure 2. One reason for this difference is that the most common treatment method is surgery. Martin et al. (1978) found that in cows with LDA that completed a lactation, milk losses were between 249 and $556 \mathrm{~kg}$. This long-term effect would decrease the average milk yield within the first $30 \mathrm{~d}$ of the lactation as shown in the current study. In this study, the method of treatment of LDA was not considered in the differences in walking activity. However, treatment differences could affect activity, and this should be kept in mind when examining activity differences.

Short-term milk yield losses occurred for all 4 disorders that were analyzed. Cows clinically diagnosed with ketosis showed a reduction in milk of $9 \mathrm{~kg} / \mathrm{d}$ on $\mathrm{d} 0$; this is similar to findings reported by King (1979), Dohoo and Martin (1984), and Deluyker et al. (1991). Lucey et al. (1986) and Rajala-Schultz et al. (1999) also showed a reduction in milk yield 2 to 4 wk before the diagnosis of ketosis. The losses in milk yield occurring after the diagnosis of 4 to $5 \mathrm{~kg} / \mathrm{d}$ have been shown in Detilleux et al. (1994). The short-term milk yield losses that occurred in cows clinically diagnosed with LDA were expected due to the long-term effects that were observed in this study and other studies. Milk yields for cows diagnosed with gas, bloat, acidosis, and off-feed were approximately 3 to $5 \mathrm{~kg} / \mathrm{d}$ less than the average yield of sick cows, and 16 to $19 \mathrm{~kg} / \mathrm{d}$ less than the average yield of healthy cows.

\section{Effects of Specific Disorders on Activity and Milk Yield}

Using activity and milk yield to detect transition cow disorders, rather than one of these tools, could give a more accurate and timely diagnosis. Figure 3 shows the difference of activity and milk yield for cows with an occurrence of ketosis, LDA, and general digestive disorders, respectively, compared with cows without an incidence of a disease in the prebreeding stage of lactation. For cows diagnosed with ketosis, LDA, or digestive disorders, activity was increased $(P<0.01)$ above that of their healthy counterparts 8 to $9 \mathrm{~d}$ before being clinically diagnosed with these disorders. The beginning days of decline for activity for cows clinically diagnosed with ketosis, LDA, and digestive disorders were 8, 9, and $8 \mathrm{~d}$, respectively, before clinical diagnoses of those disorders. This was based on changes in activity for those specifically afflicted cows and not necessarily the same time that activity differed from that of healthy cows. The activity of cows with those three disorders gradually decreased from $d-8$ to -1 relative to respec-

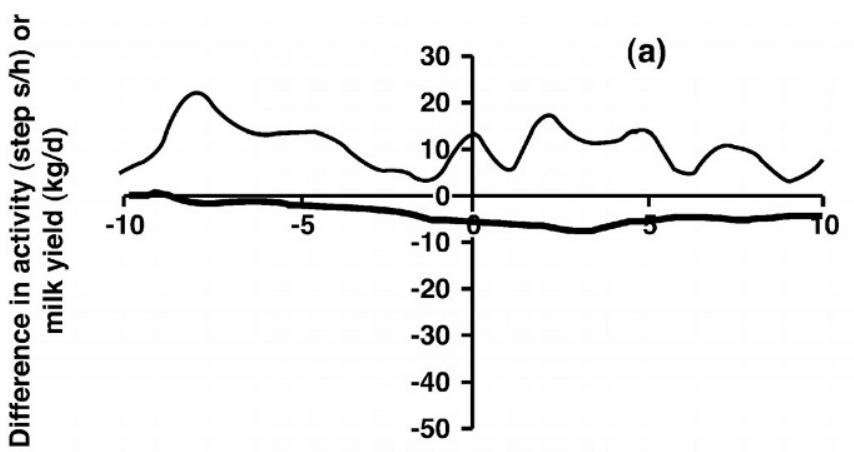

Relative to day of illness

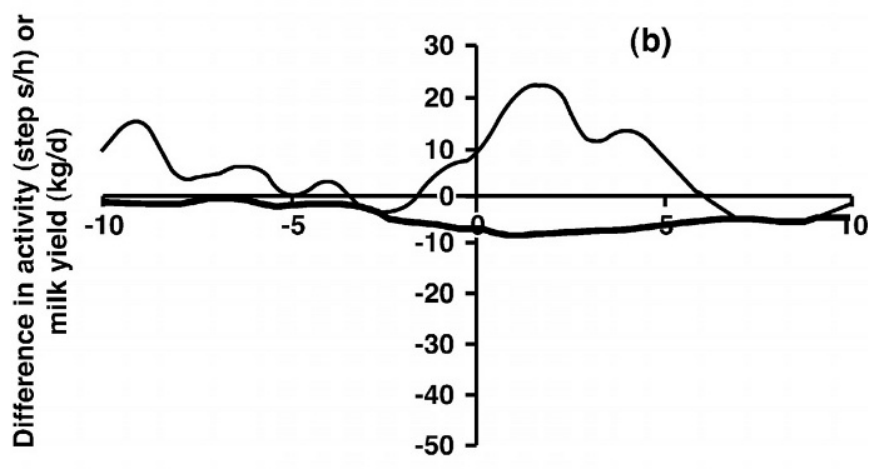

Relative to day of illness

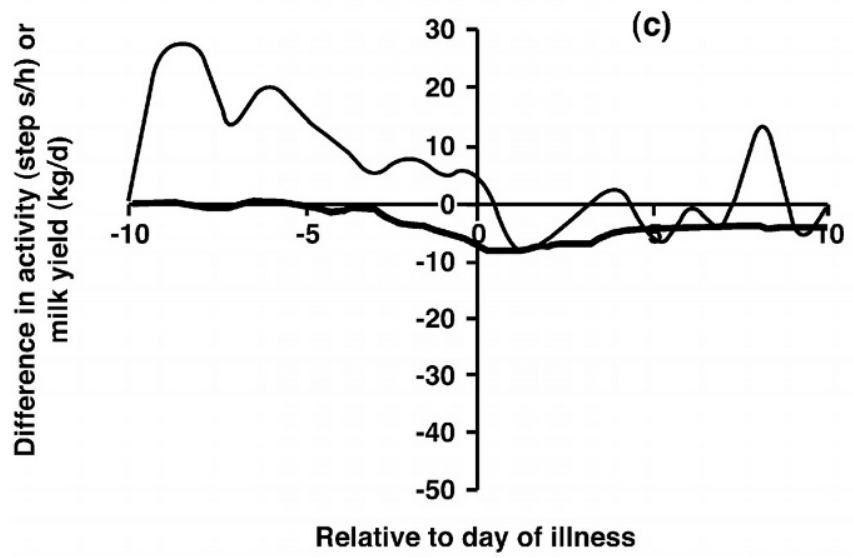

Figure 3. Difference in activity (-) and daily milk yield (-) for cows with an occurrence of ketosis (a), left displaced abomasum (LDA, b), and general digestive disorders (c), compared with cows without an incidence of a disease in the prebreeding stage during $\mathrm{d}-10$ to 10 , relative to the day of diagnosis (d 0 ). For cows diagnosed with ketosis, LDA, or digestive disorders, activity increased $(P<0.01)$ above that of their healthy counterparts 8 to 9 d before being clinically diagnosed with these disorders. The milk yield for cows diagnosed with ketosis, LDA, and digestive disorders began to decline 5 to $7 \mathrm{~d}$ before the illnesses were diagnosed.

tive days of diagnoses. The difference in activity between healthy and sick cows remained different $(P<$ 0.01 ) for cows with ketosis until $1 \mathrm{~d}$ before diagnosis. The activity of cows with digestive disorders remained 
different $(P<0.01)$ from that of healthy cows until the day of diagnosis (d 0). Cows with an LDA had variable activity, from $d-8$ to -6 , activity was higher $(P<0.01)$, from $\mathrm{d}-5$ to -2 , activity did not differ significantly from the activity of healthy cows. The activity of cows with an LDA was higher $(P<0.01) 1 \mathrm{~d}$ before clinical diagnosis. On $d 0$, there was a spike in activity for ketosis and LDA, possibly due to separating sick cows into a hospital pen or medicines positively affecting the cows. After d 0, the activity for cows diagnosed with ketosis and digestive disorders was sporadic but approximately equal or higher than healthy cows.

Milk yields began to decline $6 \mathrm{~d}$ before diagnosis for cows with ketosis, $7 \mathrm{~d}$ for those with LDA, and $5 \mathrm{~d}$ for those with digestive disorders (Figure 3). From those respective points, milk yields remained lower $(P<0.01)$ than that of healthy cows until at least $d 10$ after diagnosis. Milk yields of those sick cows gradually decreased with the most loss of production occurring on the day of diagnosis to $1 \mathrm{~d}$ after diagnosis.

Overall, activity started to decline before milk yield declined, but using only one of these detection methods could give varying results. Using both activity and milk yield to detect fresh cow disorders would give a more accurate diagnosis. Considering these results, cows clinically diagnosed with ketosis, LDA, and general digestive disorders could be diagnosed at least 5 to $6 \mathrm{~d}$ earlier based on changes in daily activity and milk yield.

The data used in this study should be analyzed using repeated measures; however, the random measures technique was used because of convergence problems with the data. Diggle et al. (1994) warns, “. . .do not attempt to fit any models which simultaneously include serial correlations as well as random effects other than intercepts."

Henderson (1982) suggested the analysis of longitudinal continuous data with a random regression mixed linear model. Random regression models vary between experimental units and are used when inferences about treatment means are made (Littell et al., 1996). The use of random regression models to analyze longitudinal traits makes it feasible to study changes over time (Meyer et al., 1989; Jakobsen et al., 2002). A random effects model assumes that correlation arises among individual repeated responses, but the regression coefficients are random across individuals. Furthermore, all of the individuals have intercepts that are in relatively close proximity to each other but have slopes that are subtly different. Hence, there is increasing variability over time across individuals (Diggle et al., 1994).

\section{CONCLUSIONS}

This study provides analysis of a new method to monitor cow health during early lactation. Advancements in technology have provided a useful tool for monitoring activity that otherwise would not be feasible due to time and cost. This tool can be used to observe dairy cows in their daily movements, including milking, eating, standing, and lying, and can detect changes in this measurement. Currently, daily walking activity is primarily being used for detection of estrus.

There were significant differences between the activity of healthy cows and the activity of cows clinically diagnosed with a metabolic or digestive disease in the prebreeding stage of lactation. The activity of dairy cows clinically diagnosed with a metabolic or digestive disorder decreased $(P<0.01) 2 \mathrm{~d}$ before the day of diagnosis when compared to healthy cows. Changes in daily walking activity, along with changes in daily milk yield, was proven to be beneficial when used to identify potential disorders during the prebreeding stage of lactation. Fresh cow disorders, such as ketosis, left displaced abomasum, and digestive disorders, could be detected 7 to $8 \mathrm{~d}$ earlier based on activity and 5 to $6 \mathrm{~d}$ earlier based on milk yield. Therefore, daily walking activity may be a useful tool when attempting to detect transition cow disorders and preventing further reduction in milk yield loss.

Year, parity, and herd effects are significant influences on activity in this study and in others, but changes in activity or trends in activity within parity on individual farms can assist in the prediction of health disorders. Also, comparing changes in the daily activity or yield of individual cows may more accurately predict disease incidence than comparing individual cow activity or yield to averages for herds or parity groups.

\section{ACKNOWLEDGMENTS}

The authors would like to thank Joan Cooper, Rob Goodling, and Chad Dechow for their SAS support, as well as Naomi Altman for statistical analysis advice. We would also like to thank Gary Rogers for providing these data.

\section{REFERENCES}

Deluyker, H. A., J. M. Gay, L. D. Weaver, and A. S. Azari. 1991. Change of milk yield with clinical diseases for a high producing dairy herd. J. Dairy Sci. 74:436-445.

Detilleux, J. C., Y. T. Gröhn, and R. L. Quaas. 1994. Effects of clinical ketosis on test day milk yields in Finnish Ayrshire cattle. J. Dairy Sci. 77:3316-3323.

Diggle, P. J., K. Liang, and S. L. Zeger. 1994. Analysis of Longitudinal Data. Oxford University Press, New York, NY.

Dohoo, I. R., and S. W. Martin. 1984. Subclinical ketosis: Prevalence and associations with production and disease. Can. J. Comp. Med. 48:1-5.

Fourichon, C., H. Seegers, N. Bareille, and F. Beaudeau. 1999. Effects of disease on milk production in the dairy cow: A review. Prev. Vet. Med. 41:1-35. 
Grant, R. J., and J. L. Albright. 1995. Feeding behavior and management factors during the transition period in dairy cattle. J. Anim. Sci. 73:2791-2803.

Gröhn, Y. T., Y. H. Schukken, J. A. Hertl, and S. W. Eicker. 1999 Analysis of correlated continuous repeated observations: Modelling the effect of ketosis on milk yield in dairy cows. Prev. Vet. Med. 39:137-153.

Heinrichs, A. J., V. A. Ishler, and R. S. Adams. 1996. Feeding and managing dry cows. Extension Circular 372. College of Agricultural Sciences, Cooperative Extension, The Pennsylvania State University, University Park.

Henderson, C. R., Jr. 1982. Analysis of covariance in the mixed model: Higher-level nonhomogeneous, and random regression. Biometrics 38:623-640.

Jakobsen, J. H., P. Madsen, J. Jensen, J. Pedersen, L. G. Christensen, and D. A. Sorensen. 2002. Genetic parameters for milk production and persistency for Danish Holsteins estimated in random regression models using REML. J. Dairy Sci. 85:1607-1616.

King, J. O. L. 1979. The effects of ketosis in dairy cows on body weight, milk yield and milk composition. Br. Vet. J. 135:40-43.

Littell, R. C., G. A. Milliken, W. W. Stroup, and R. D. Wolfinger. 1996. SAS System for Mixed Models. SAS Institute Inc. Cary, NC.

Lucey, S., G. J. Rowlands, and A. M. Russell. 1986. Short-term associations between disease and milk yield of dairy cows. J. Dairy Res. $53: 7-15$.
Martin, S. W., K. L. Kirby, and R. A. Curtis. 1978. Left abomasal displacement in dairy cows: Its relationship to production. Can. Vet. J. 19:250-253.

Meyer, K., H.-U. Graser, and K. Hammond. 1989. Estimates of genetic parameters for first lactation test day production of Australian black and white cows. Livest. Prod. Sci. 21:177-199.

Moallem, U., P. Gur, N. Shpigel, E. Maltz, N. Livshin, S. Yacoby, A. Antman, and E. Aizinbud. 2002. Graphic monitoring of the course of some clinical conditions in dairy cows using a computerized dairy management system. Israel J. Vet. Med. 57:43-64.

Østergaard, S., and Y. T. Gröhn. 1999. Effects of diseases on test day milk yield and body weight of dairy cows from Danish research herds. J. Dairy Sci. 82:1188-1201.

Perera, K. S., F. C. Gwazdauskas, R. E. Pearson, and T. B. Brumback, Jr. 1986. Effect of season and stage of lactation on performance of Holsteins. J. Dairy Sci. 69:228-236.

Rajala-Schultz, P. J., Y. T. Gröhn, and C. E. McCulloch. 1999. Effects of milk fever, ketosis, and lameness on milk yield in dairy cows. J. Dairy Sci. 82:288-294.

Schultz, L. H. 1988. Milk fever, ketosis, and the fat cow syndrome. Pages 493-509 in The Ruminant Animal: Digestive Physiology and Nutrition. D. C. Church, ed. Prentice-Hall, Inc., Englewood Cliffs, NJ.

Tomaszewski, M. A. 1993. Record-keeping systems and control of data flow and information retrieval to manage large high producing herds. J. Dairy Sci. 76:3188-3194. 